\title{
COMPARISON OF NEFOPAM HYDROCHLORIDE AND PROPOXYPHENE HYDROCHLORIDE IN THE TREATMENT OF POSTOPERATIVE PAIN
}

\author{
D. TROP, L. KENNY AND B.R. GRAD
}

SeVere postoperative paIN is normally relieved with potent narcotic drugs while moderate acute pain is treated with mild analgesics. These substances have been divided into three chemically unielated groups which provide for adequate pain relief with either a parenteral or oral formulation. ${ }^{1,2}$

In recent years, a new non-narcotic analgesic benzoxazocine, a complex heterocyclic structure, was synthetized by cyclization of diphenhydramine. ${ }^{3}$ The new agent, nefopam hydrochloride has considerably less anti-cholinergic and antihistaminic activity than its parent structure and a lower acute toxicity. Clinical studies have confirmed the analgesic action of nefopam. ${ }^{4-6}$ Sunshine and Laska7 have estimated the relative potency of nefopam to morphine and found $20 \mathrm{mg}$ of nefopam $\mathrm{HCl}$ to be the analgesic equivalent of $12 \mathrm{mg}$ of morphine sulfate, while Tigerstedt, et al. reported nefopam $15 \mathrm{mg}$ as equipotent to meperidine $50 \mathrm{mg}$. Workmon and Winter ${ }^{5}$ have indicated nefopam to be 8.4 times as potent as aspirin on a milligram per milligram basis.

The purpose of the present double-blind parallel study was to compare the analgesic activity of nefopam hydrochloride relative to propoxyphene hydrochloride and a placebo when administered by mouth.

\section{Materials and Methods}

One hundred and twenty-five in-patients of either sex were selected for this study. They were between 18 and 73 years of age, suffering from moderate to severe postoperative pain on the day following operation or on the two subsequent days. Informed consent was obtained from all subjects. Patients who received analgesics, tranquilizers or anaesthetic agents within six hours of the first administration of the test medication, patients with a history of convulsive disorders,

D. Trop, M.D., F.R.C.P.(C), L. Kenny, R.N. and B.R. Grad, Ph.D., Department of Anaesthesia, Montreal Neurological Institute, 3801 University Street, Montreal, Quebec, H3A 2B4.

This study was supported by Riker Laboratories, Inc, St. Paul, Minnesota, U.S.A.

Canad. Anaesth. Soc. J., vol. 26, no. 4, July 1979 with significant hepatic or renal disease, pregnant women, and patients admitted for intracranial operations were excluded from the study. Patients fulfilling these criteria were randomly assigned to one of five treatment groups. Groups and 2 received 65 and $130 \mathrm{mg}$ d-propoxyphene $\mathrm{HCl}$ respectively, groups 3 and 4 received 60 and $90 \mathrm{mg}$ nefopam $\mathrm{HCl}$ respectively and group 5 received a placebo.

Pain intensity was rated on a four-point scale $(0=$ no pain, 1 = slight pain, $2=$ moderate pain and $3=$ severe pain) at baseline, and at $0.5,1,2$, $3,4,5$, and 6 hours following treatment.

Pain relief was assessed on a five-point scale ( 0 = none, $1=$ slight, 2 = moderate, $3=$ good, and $4=$ complete) at the same times.

If the patient's pain was not relieved by the test medication and he was unable to wait at least four hours, he was given a conventional analgesic. Pain relief and pain intensity were not recorded from that point on.

The assessment of efficacy was based on the analysis of pain intensity scores, pain intensity differences scores, weighted sum of pain intensity differences, pain relief scores, and weighted total pain relief scores. ${ }^{8}$ Pain intensity differences were calculated for each observation by subtracting the pain intensity at that moment from baseline values. The weighted sum of the pain intensity differences is obtained by multiplying each pain intensity difference by the fraction of an hour since the previous observation and adding the result across all observations for each patient. Pain relief scores were similarly weighted and totalled for all post-medication observations to provide another estimate of analgesia.

A record of side effects by type and severity was made for each case. Secondary reactions were related to the tegumentary system (dry mouth, sweating) the cardiovascular system (tachycardia, hypotension, flushing, sensation of warmth), the digestive system (nausea, vomiting), the nervous system (dizziness, lightheadedness, numbness, tingling in the extremities, vertigo, agitation, auditory or visual disturbances), the psyche (dreams, euphoria, floating, groggi- 
TABLE I

Vital Data of All Patients

\begin{tabular}{|c|c|c|c|c|c|}
\hline & \multicolumn{2}{|c|}{ d-Propoxyphene } & \multicolumn{2}{|c|}{ Nefopam HCl } & \multirow[b]{2}{*}{ Placebo } \\
\hline & $65 \mathrm{mg}$ & $130 \mathrm{mg}$ & $60 \mathrm{mg}$ & $90 \mathrm{mg}$ & \\
\hline $\begin{array}{l}\text { Age (year) } \\
\text { Height (cm) } \\
\text { Weight (kg) } \\
\text { Sex (M) } \\
\quad \text { (F) }\end{array}$ & $\begin{array}{l}40.8(12.0) \\
173(6.3) \\
73.0(11.3) \\
18 \\
7\end{array}$ & $\begin{array}{l}34.4(14.0) \\
172(8.5) \\
68.6(10.3) \\
18 \\
7\end{array}$ & $\begin{array}{l}41.7(15.6) \\
169(10.0) \\
71.7(14.3) \\
14 \\
11\end{array}$ & $\begin{array}{l}38.4(15.4) \\
171(9.1) \\
72.6(15.1) \\
16 \\
9\end{array}$ & $\begin{array}{l}36.4(16.9) \\
172(8.8) \\
71.8(11.3) \\
19 \\
6\end{array}$ \\
\hline \multicolumn{6}{|c|}{ Initial pain intensity } \\
\hline $\begin{array}{l}\text { Acute } \\
\text { Moderate } \\
\text { Mean }\end{array}$ & $\begin{array}{r}6 \\
19 \\
2.24\end{array}$ & $\begin{array}{r}6 \\
19 \\
2.24\end{array}$ & $\begin{array}{r}5 \\
20 \\
2.20\end{array}$ & $\begin{array}{r}5 \\
20 \\
2.20\end{array}$ & $\begin{array}{c}3 \\
22 \\
2.12\end{array}$ \\
\hline
\end{tabular}

Mean values and standard deviations.

ness, high, shakiness, drowsiness, withdrawal), metabolic disturbances (cold, clammy skin), and others (headache, tiredness, itching, weakness). Severity was classified as none, slight, moderate or severe.

Chi-square tests for contingency tables, or Fisher's exact test, where applicable, were used to analyze the single data. For group, scored and continuous data, non-parametric multiple comparison procedures, were used.

If overall treatment differences were found to be statistically significant $(p<0.05)$ all pairwise treatment differences were tested for their statistical significance using both non-parametric and parametric multiple comparison techniques.

In the analysis, any patient who had requested an additional analgesic before the end of the evaluation period retained, throughout the subsequent observation time, the pain intensity score recorded at that moment; he was also considered as having had no pain relief from that time on.

A six-hour interval between the last intake of a standard analgesic and the beginning of the present study had been considered as a prerequisite for any patient to enter the study. It appeared that in 47 patients the protocol had been violated and that patients who had received an analgesic within four to six hours before administration of the investigational drug had been accepted. The study was not considered invalid, but separate analyses were performed.

\section{Results}

The physical characteristics of all patients are presented in Table I with their initial pain inten-
TABLE II

Distribution by Sites of Pain

\begin{tabular}{|c|c|c|c|c|c|}
\hline & \multicolumn{2}{|c|}{ Propoxyphene } & \multicolumn{2}{|c|}{ Nefopam } & \multirow[b]{2}{*}{ Placebo } \\
\hline & $\begin{array}{c}65 \\
\mathrm{mg}\end{array}$ & $\begin{array}{l}130 \\
\mathrm{mg}\end{array}$ & $\begin{array}{c}60 \\
\mathrm{mg}\end{array}$ & $\begin{array}{l}90 \\
\mathrm{mg}\end{array}$ & \\
\hline $\begin{array}{l}\text { Neck } \\
\text { Chest }\end{array}$ & $\begin{array}{l}1 \\
1\end{array}$ & 1 & & 1 & 1 \\
\hline Arms, Hands & 1 & 3 & 1 & 2 & 2 \\
\hline Back, Shoulders & 6 & 3 & 5 & 3 & 3 \\
\hline Legs, Foot & 16 & 18 & 19 & 19 & 19 \\
\hline Total & 25 & 25 & 25 & 25 & 25 \\
\hline
\end{tabular}

sity status. One hundred and twenty-five patients entered the study: 25 received propoxyphene $65 \mathrm{mg}$ (6 severe and 19 moderate); 25 received propoxyphene $130 \mathrm{mg}$ (6 severe and 19 moderate); 25 received nefopam $60 \mathrm{mg}$ ( 5 severe and 20 moderate); 25 received nefopam $90 \mathrm{mg}$ ( 5 severe and 20 moderate); 25 received a placebo ( 3 severe and 22 moderate).

The distribution of patients by pain sites is shown in Table II. It shows a bias towards surgical procedures on the lower extremities. This resulted from the design of the study which, by using solely an oral form of medication, excluded all abdominal surgical patients.

A total of 85 males and 40 females entered the study. The reason for the disparity in the enrolment by sex might be due to a larger proportion of refusals by women to participate than by males. Also because of the large number of orthopaedic surgical cases, many Workers' Compensation cases were included in the study, and majority of these were men.

The patients ranged in age from 18 to 73 years with a mean of 38.6 years. Height ranged from 
TABLE III

Effect of Propoxyphene, Nefopam or Placebo on the Pain Intensity and Pain Relief Experienced by All the Patients Postoperatively (Analysis I)

\begin{tabular}{|c|c|c|c|c|c|c|}
\hline & \multirow{2}{*}{$\begin{array}{c}\text { Time after } \\
\text { drug given } \\
\text { (hours) }\end{array}$} & \multicolumn{2}{|c|}{ Propoxyphene } & \multicolumn{2}{|c|}{ Nefopam } & \multirow[b]{2}{*}{ Placebo } \\
\hline & & $65 \mathrm{mg}$ & $130 \mathrm{mg}$ & $60 \mathrm{mg}$ & $90 \mathrm{mg}$ & \\
\hline Mean pain intensity (PI) & 2 & 1.20 & $0.96 * t$ & $0.96^{*} \ddagger$ & 1.24 & 1.68 \\
\hline $\begin{array}{l}\text { Mean pain intensity } \\
\text { differences (PID) }\end{array}$ & $\begin{array}{l}2 \\
3\end{array}$ & $\begin{array}{l}1.04 \\
0.80\end{array}$ & $\begin{array}{l}1.28+\S \\
0.96+\S\end{array}$ & $\begin{array}{l}1.24+8 \\
0.96+8\end{array}$ & $\begin{array}{l}0.96 \\
0.64\end{array}$ & $\begin{array}{l}0.44 \\
0.24\end{array}$ \\
\hline SPID up to 4 hours & & 3.00 & $3.56^{\circ} t$ & $3.52 * t$ & 2.44 & 1.32 \\
\hline SPID up to 6 hours & & 3.52 & $4.04 * t$ & 3.76 & 2.84 & 1.44 \\
\hline Mean pain relief (PR) & $\begin{array}{l}2 \\
3\end{array}$ & $\begin{array}{l}1.84 \\
1.52\end{array}$ & $\begin{array}{l}2.36+8 \\
1.88+8\end{array}$ & $\begin{array}{l}2.28+8 \\
1.80+8\end{array}$ & $\begin{array}{l}2.08 * \ddagger \\
1.36\end{array}$ & $\begin{array}{l}0.76 \\
0.40\end{array}$ \\
\hline $\begin{array}{l}\text { Mean total pain relief } \\
\text { (WTOTPAR) up to } 6 \text { hours }\end{array}$ & & 6.66 & $7.96 * f$ & $7.20 *+$ & 6.40 & 2.76 \\
\hline Number of patients & & 25 & 25 & 25 & 25 & 25 \\
\hline
\end{tabular}

*Significant differences from placebo, $p<0.05$ (Student-Neuman Keuls).

†Significant difierences from placebo, $p<0.01$ (Student-Neuman Keuls)

†Significant differences from placebo, $p<0.05$ (Dunn's multiple comparison method).

\$Significant difierences from placebo, $\mathrm{p}<0.01$ (Dunn's multiple comparison method).

$137.1 \mathrm{~cm}$ to $193.0 \mathrm{~cm}$, and weight from $46.3 \mathrm{~kg}$ to $102.5 \mathrm{~kg}$.

The comparability of patients in the five treatment groups was assessed with regard to a number of different demographic, diagnostic, and clinical factors, these being age, sex, weight, height, pain site and initial pain intensity.

Except for the distribution of males and females within treatment groups and the age of males and females in the propoxyphene $65 \mathrm{mg}$ and the placebo treatment group, treatment groups were found to be generally comparable.

As noted earlier, 47 patients were found to have violated the protocol in having received analgesic medication before the study. Of these, 11 patients were in the nefopam $60 \mathrm{mg}$ group (4 $\mathrm{hr}, 59 \mathrm{~min}$ ), eight patients in the nefopam $90 \mathrm{mg}$ group $(5 \mathrm{hr}, 08 \mathrm{~min}), 13$ patients in the propoxyphene $65 \mathrm{mg}$ group ( $4 \mathrm{hr}, 40 \mathrm{~min}$ ), seven patients in the propoxyphene $130 \mathrm{mg}$ group $(5 \mathrm{hr}$, $8 \mathrm{~min}$ ), eight patients in the placebo group ( $4 \mathrm{hr}$, $46 \mathrm{~min}$ ). Separate analyses were done of the results including all patients (I), all patients with violators removed (II) and violators only (III). They showed small variations between groups I \& II. In group III, the total number of patients being much smaller, no statistically significant pairwise treatment differences were observed for any of the efficacy measurements. Treatment differences are. therefore, presented for only groups I \& II (Tables III \& IV). Graphic evidence

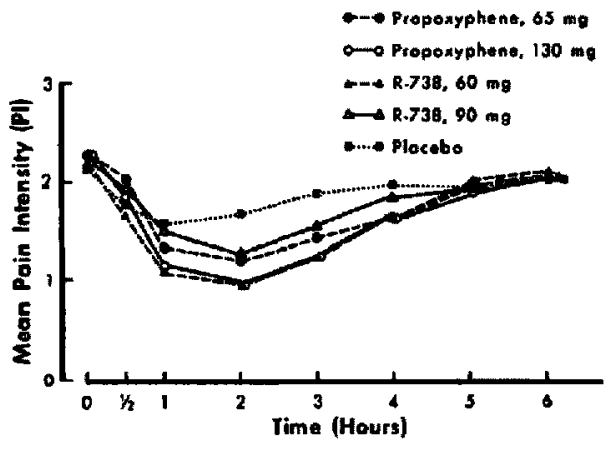

Figure I The effect of propoxyphene, nefopam and placebo on the postoperative mean pain intensity of all patients in the study.

of the course of events is presented for each group and for each parameter, as a demonstration of similar if not identical patterns (Figures 1-9).

Pain Intensity: Analysis I showed the treatment group to be significantly different in pain intensity at two hours after administration (Table III, Figure I, $p<0.01$ ). The individual comparisons of nefopam $60 \mathrm{mg}$ vs placebo and of propoxyphene $130 \mathrm{mg}$ vs placebo were significantly different ( $p<0.05$ ). Analysis II (Figure 2$)$ showed treatment differences at two $(p<0.03)$ and three hours $(p<0,02$ ), but none of the individual comparisons were statistically significant.

Pain Intensity Differences: With analysis I 
TABLE IV

Effect of Propoxyphene, Nefopam or Placebo on the Pain Intensity and Pain Relief Experienced Postoperatively by Patients In Whom the Protocol. Had Not Been Violated (Analysis II)

\begin{tabular}{|c|c|c|c|c|c|c|}
\hline & \multirow{2}{*}{$\begin{array}{l}\text { Time after } \\
\text { drug given } \\
\text { (hours) }\end{array}$} & \multicolumn{2}{|c|}{ Propoxyphene } & \multicolumn{2}{|c|}{ Nefopam } & \multirow[b]{2}{*}{ Placebo } \\
\hline & & $65 \mathrm{mg}$ & $130 \mathrm{mg}$ & $60 \mathrm{mg}$ & $90 \mathrm{mg}$ & \\
\hline $\begin{array}{l}\text { Mean pain intensity } \\
\text { difference (PID) }\end{array}$ & $\begin{array}{l}2 \\
3\end{array}$ & $\begin{array}{l}1.25 \\
1.08\end{array}$ & $\begin{array}{l}1.39 * \ddagger \\
1.11 * \ddagger\end{array}$ & $\begin{array}{l}1.36 \\
1.21 * \ddagger\end{array}$ & $\begin{array}{l}1.00 \\
0.77\end{array}$ & $\begin{array}{l}0.47 \\
0.24\end{array}$ \\
\hline $\begin{array}{l}\text { Sum of pain intensity } \\
\text { difference to } 4 \text { hours }\end{array}$ & & 3.67 & $4.03 * t$ & $4.18 * \ddagger$ & 2,68 & 1.41 \\
\hline $\begin{array}{l}\text { Sum of pain intensity } \\
\text { difference to } 6 \text { hours }\end{array}$ & & 4.42 & 4.69 & 4.61 & 3.15 & 1.53 \\
\hline Mean pain relief & $\begin{array}{l}2 \\
3\end{array}$ & $\begin{array}{l}2.33 \\
2.00\end{array}$ & $\begin{array}{l}2.50+\$ \\
2.11+\$\end{array}$ & $\begin{array}{l}2.43 * \ddagger \\
2.14+\S\end{array}$ & $\begin{array}{l}2.24^{*} \ddagger \\
1.59\end{array}$ & $\begin{array}{l}0.77 \\
0.35\end{array}$ \\
\hline $\begin{array}{l}\text { Mean total pain relief up to } \\
6 \text { hours }\end{array}$ & & 8.54 & $9.03 * \ddagger$ & 8.43 & 7.21 & 2.68 \\
\hline Number of patients & & 12 & 18 & 14 & 17 & 17 \\
\hline
\end{tabular}

*Significant differences from placebo, p $<0.05$ (Student-Neuman Keuls)

tSignificant differences from placebo, $p<0.01$ (Student-Neuman Keuls)

tSignificant differences from placebo, $\mathrm{p}<0.05$ (Dunn's multiple comparison method).

Significant differences from placebo, $p<0.01$ (Dunn's multiple comparison method).

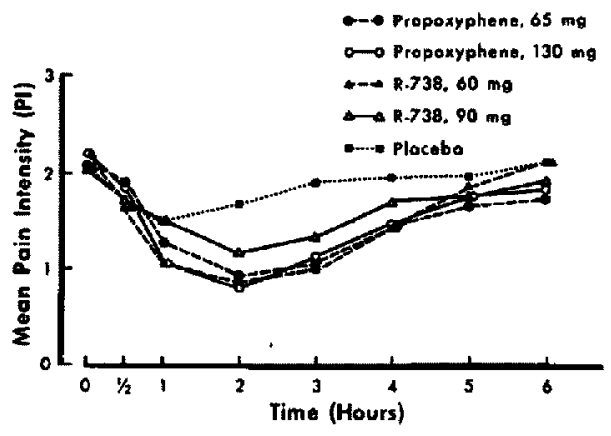

FIGURE 2 The effect of propoxyphene, nefopam or placebo on the postoperative mean pain intensity of patients in whom the protocol had not been vialated.

(Table III, Figure 3) the treatments were found significantly different at two $(p<0.002)$ and three hours $(p<0.004)$ after administration. At both two and three hours, the individual comparisons of nefopam $60 \mathrm{mg}$ vs placebo and of propoxy. phene $130 \mathrm{mg}$ vs placebo were significant ( $p<$ 0.01). With analysis II (Table IV, Figure 4) treatment differences were observed at hour two $(p<$ $0.02)$ and hour three $(p<0.005)$. At two hours, the individual comparison of propoxyphene $130 \mathrm{mg}$ vs placebo was significant $(p<0.05)$. At three hours, the individual comparisons of nefopam $60 \mathrm{mg}$ vs placebo, and propoxyphene

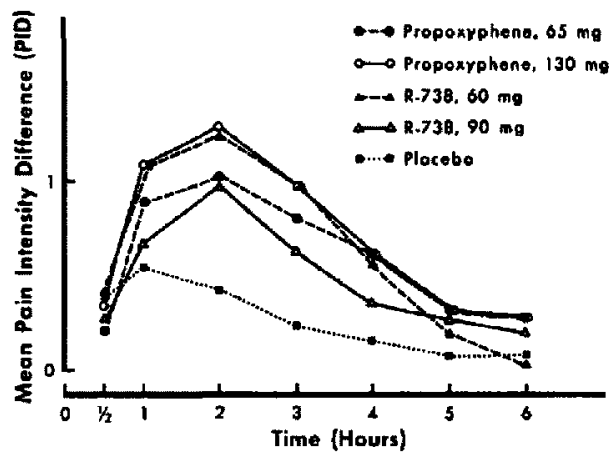

FIGURE 3 The effecl of propoxyphene, nefopam or placebo on the postoperative mean pain intensity difference of all patients in the study.

$130 \mathrm{mg}$ vs placebo were found to be significant $(\mathrm{p}<0.05)$.

Weighted Sum of Pain Intensity Differences: In all patients (Table III) all treatments but one were found to be significantly different ( $p<$ 0.003 ). The individual comparisons of propoxyphene $130 \mathrm{mg}$ vs placebo and of nefopam $60 \mathrm{mg}$ vs placebo were found to be significant after four hours $(p<0.05)$, whereas only propoxyphene $130 \mathrm{mg}$ vs placebo was found to be significant after six hours $(p<0.05)$. With the violators removed (Table IV), treatment differences were observed among sums of pain intensity differ- 


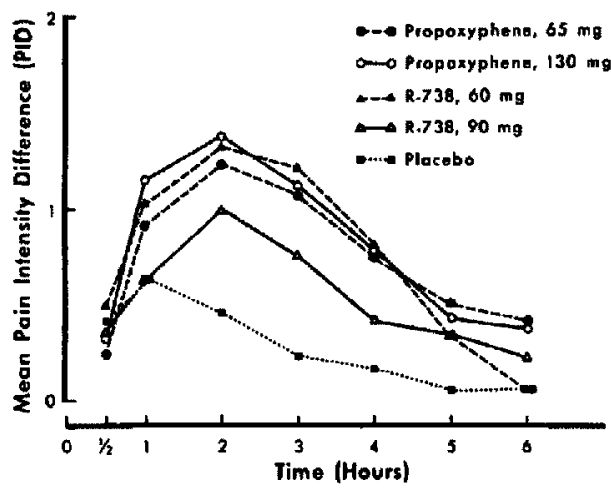

FIGURE 4 The effect of propoxyphene, nefopam or placebo on the postoperative mean pain intensity difference of patients in whom the protocol had not been violated.

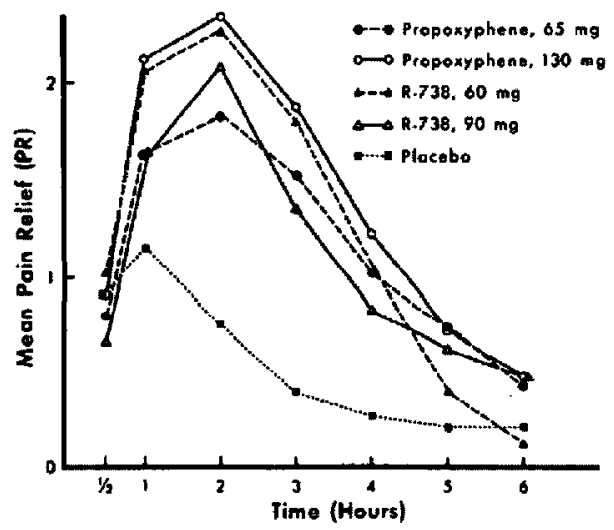

Figure 5 The effect of propoxyphene, nefopam or placebo on the postoperative mean pain relief of all the patients in the study.

ences $(p<0.01)$ and the individual comparisons, nefopam $60 \mathrm{mg}$ vs placebo and propoxyphene $130 \mathrm{mg}$ vs placebo were found to be significant after four hours $(p<0.05)$.

Pain Relief Scores: Analysis I (Table III, Figure 5) showed treatment differences at two and three hours $(\mathrm{p}<0.002$ and $\mathrm{p}<0.03$ respectively). At two hours the individual comparisions, nefopam $60 \mathrm{mg}$ vs placebo and propoxyphene $130 \mathrm{mg}$ vs placebo, were found to be significant ( $p<0.01$ ) and nefopam $90 \mathrm{mg}$ vs placebo was also significant $(p<0.05)$. At three hours the individual comparisons, nefopam $60 \mathrm{mg}$ vs placebo and propoxyphene $130 \mathrm{mg}$ vs placebo, were again found to be significant $(p<0.01$ ). Analysis II (Table IV, Figure 6) revealed treatment differ-

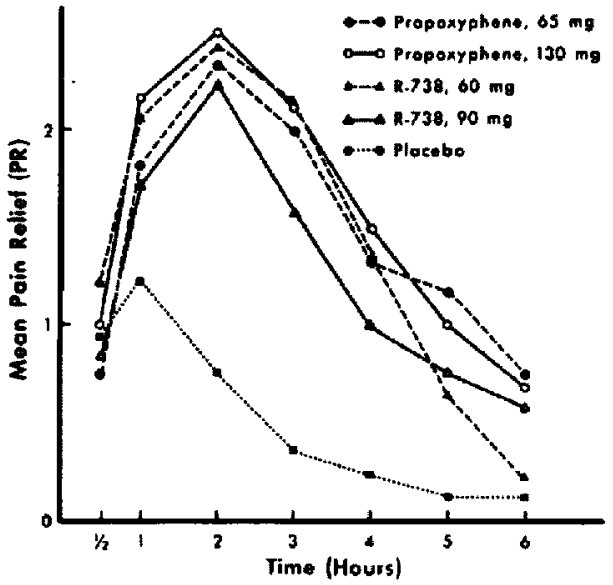

FIGURE 6 The effect of propoxyphene, nefopam or placebo on the postoperative mean pain relief of patients in whom the protocol had not been violated.

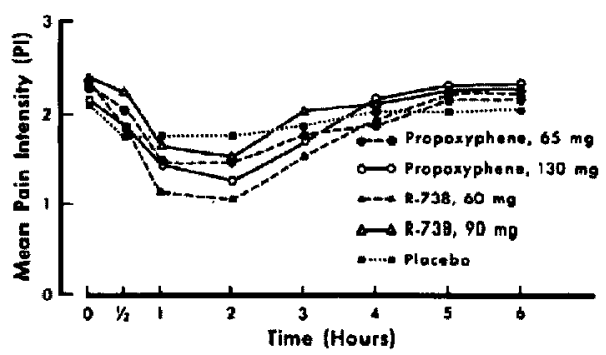

Figure 7 The effect of propoxyphene, nefopam or placebo on the postoperative mean pain intensity of patients in whom the protocol had been violated.

ences at two hours $(p<0.004)$ and three hours ( $p$ $<0.003$ ). At two hours the individual comparisons, nefopam $60 \mathrm{mg}$ vs placebo and nefopam $90 \mathrm{mg}$ vs placebo, were significant $(p<0.05)$. The comparison of propoxyphene $130 \mathrm{mg}$ vs placebo was also significant $(p<0.01)$ two hours after the start of treatment. At three hours the individual comparisons, propoxyphene $130 \mathrm{mg}$ vs placebo and nefopam $60 \mathrm{mg}$ vs placebo, were statistically significant $(\mathrm{p}<0.01)$.

Weighted Total Pain Relief Scores: Treatment differences were found to be significant with Analysis I ( $p<0.002)$ and Analysis II ( $<<0.007$ ). The individual comparisons, nefopam $60 \mathrm{mg}$ vs placebo and propoxyphene $130 \mathrm{mg}$ vs placebo. were found to differ significantly $(p<0.05)$ in Analysis I (Table III), while only the comparison of propoxyphene $130 \mathrm{mg}$ vs placebo was significant $(\mathrm{p}<0.05)$ in Analysis II (Table IV). 
TABLE $V$

The Frequency of Side Effects Reported By The Patients Receiving Propoxy PHene, Nefopam or Placebo Postoperatively

\begin{tabular}{lccccccc}
\hline & \multicolumn{2}{c}{ Propoxyphene } & \multicolumn{2}{c}{ Nefopam } & & \\
\cline { 2 - 3 } & $65 \mathrm{mg}$ & $130 \mathrm{mg}$ & $60 \mathrm{mg}$ & $90 \mathrm{mg}$ & Placebo & Total \\
\hline $\begin{array}{l}\text { No. of patients } \\
\text { No. of patients } \\
\text { without side effects }\end{array}$ & 25 & 25 & 25 & 25 & 25 & 125 \\
$\begin{array}{l}\text { No. of patients with } \\
\text { reported side effects }\end{array}$ & 19 & 23 & 23 & 21 & 10 & 96 \\
$\begin{array}{c}\text { No. of reported side } \\
\text { effects }\end{array}$ & 37 & 46 & 53 & 45 & 15 & 196 \\
$\begin{array}{c}\text { No. of significant } \\
\text { side effects }\end{array}$ & 24 & 28 & 34 & 31 & 9 & 117 \\
\hline
\end{tabular}

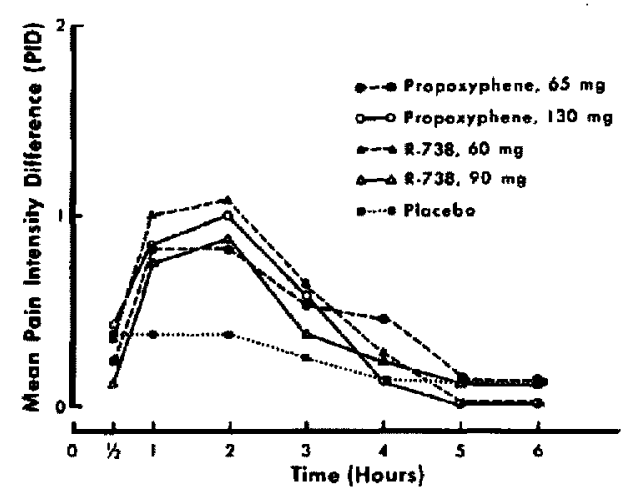

Figure 8 The effect of propoxyphene, nefopam or placebo on the postoperative mean pain intensity difference of patients in whom the protocol had been violated.

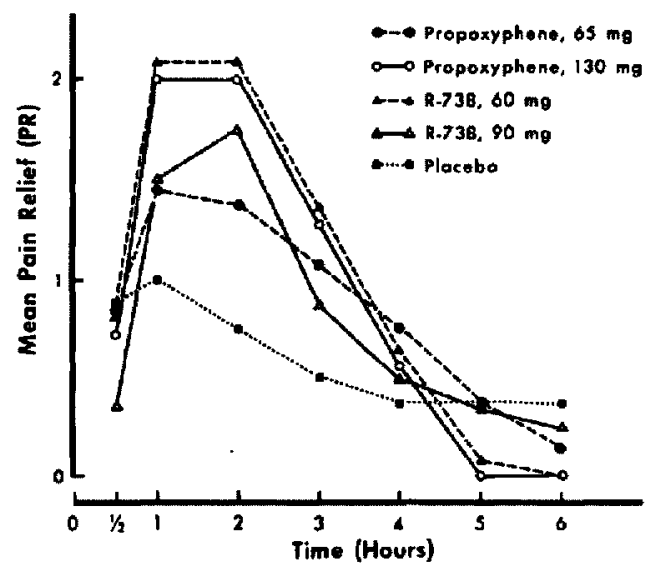

Figure 9 The effect of propoxyphene, nefopam or placebo on the postoperative relief of patients in whom the protocol had been violated.
TABLE VI

Type of Side Effects Reported by THe Patents Receiving Propoxyphene, Nefopam or Placebo Postoperatively

\begin{tabular}{|c|c|c|c|c|c|}
\hline & \multicolumn{2}{|c|}{ Propoxyphene } & \multicolumn{2}{|c|}{ Nefopam } & \multirow[b]{2}{*}{ Placebc } \\
\hline & $\begin{array}{c}65 \\
\mathrm{mg}\end{array}$ & $\begin{array}{c}130 \\
\mathrm{mg}\end{array}$ & $\begin{array}{r}60 \\
\mathrm{mg}\end{array}$ & $\begin{array}{c}90 \\
\mathrm{mg}\end{array}$ & \\
\hline Dry mouth & 3* & $5 *$ & 1 & & 2 \\
\hline Sweating & 2 & 3 & $13^{*}+$ & $10 * t$ & \\
\hline $\begin{array}{l}\text { Tachycardia } \\
\text { Lighted- }\end{array}$ & & 2 & $3 t$ & $3 f$ & \\
\hline headedness & $5 *+$ & $3 * t$ & & & \\
\hline Grogginess & $4 t$ & $5+$ & 2 & 2 & \\
\hline Sleepiness & $11 \dagger$ & $12+$ & $13+$ & $14 t$ & 8 \\
\hline Tiredness & 2 & 4 & $6+$ & $4 t$ & 2 \\
\hline
\end{tabular}

*Significant difference between Nefopam and Propoxyphene at $\mathrm{p}=0.05$.

+ Significant difference from Placebo at $p=0.05$.

No study had to be discontinued because of side effects. However, only 29 patients reported no side effects whatever, while 96 patients complained of one or more secondary reactions (Table V). The patients who received a placebo had markedly fewer side effects and did not report any cardiovascular, digestive or nervous reactions. Among the side effects reported (Table VI), significantly more occurrences of lightheadedness, grogginess and sleepiness were reported for propoxyphene than for placebo. Significantly more cases of sweating, tachycardia, sleepiness and tiredness were observed for nefopam than for placebo. In comparing propoxyphene to nefopam, significantly more instances of dry mouth and light-headedness were reported for propoxyphene and significantly more sweating was reported for nefopam. 
Several patients requested additional analgesics before the end of the observation period. Various "pain killers" were used randomly with the treatment groups and no differences were observed between them.

\section{Discussion}

In planning this study, great care was taken to avoid the pitfalls which have diminished the value of many earlier studies with analgesic drugs. It was, therefore, decided to follow closely all ten recommendations of W.T. Beaver' pertinent to the design and interpretation of analgesic essays. For the same reason, a well-accepted and timeproven programme by Laska, et al. ${ }^{8}$ was used for statistical analysis of the results.

D-propoxyphene was selected as the analgesic standard for comparison, to complete a series of comparative evaluations between nefopam $\mathrm{HCl}$ and other common analgesic drugs. ${ }^{4-7,9}$ Although the credentials of d-propoxyphene are at least equivocal, ${ }^{10.11}$ the drug still remains one of the most popular. It should also be recognized that the majority of criticisms were directed towards the lower $32 \mathrm{mg}$ dose, with fewer involving the $65 \mathrm{mg}$ dose and none the larger $130 \mathrm{mg}$ dose. In his general review of the mild analgesics, Beaver ${ }^{1}$ declared d-propoxyphene $65 \mathrm{mg}$ superior to placebo, while Cass and Frederick'12 found $130 \mathrm{mg}$ d-propoxyphene to be superior to a $65 \mathrm{mg}$ dose for pain relief. Our study demonstrated unequivocally that the larger dose was different from the placebo, and much more effective than the lower $65 \mathrm{mg}$ dose.

In the present study nefopam $60 \mathrm{mg}$ was equipotent with d-propoxyphene $130 \mathrm{mg}$ and at these concentrations both drugs were significantly more active than a placebo. Statistical differences between the drugs and a placebo appeared only at two and three hours, depending on the parameter considered. Why statistical differences did not appear earlier might be worth considering. First, as observed by Beecher ${ }^{13}$ the greater the stress, the more effective the placebo effect. During the first hour of observation one might expect the stress to have been at its highest level, resulting in higher placebo scores and, therefore, lesser differences between the various groups. Greater expectations on the part of the patients early in the study could also have resulted in artificially elevated score values in the placebo group.

Second, the greater efficacy at two hours and three hours might be indicative of the time lag between intake and full action of the drugs, as well as the duration of effect. As reported by Cohen, ${ }^{4}$ peak plasma levels of 29 to $67 \mathrm{mcg} / \mathrm{ml}$ after oral dosage of nefopam $60 \mathrm{mg}$ were attained at about two hours after administration, while the plasma half-life averaged four hours. A close analysis of our data indicates that d-propoxyphene and nefopam in both concentrations became effective after the first hour and lasted for at least another two hours. The analgesic effect of d-propoxyphene $130 \mathrm{mg}$ and $65 \mathrm{mg}$ lasted longer than that of nefopam $60 \mathrm{mg}$, but the onset of relief observed with nefopam $60 \mathrm{mg}$ was faster than with propoxyphene. For reasons unknown, nefopam $90 \mathrm{mg}$ did worse than the three other test samples, except at hour two. The onset of action with nefopam $90 \mathrm{mg}$ was remarkably slow, the duration very short and the peak did not reach that of nefopam $60 \mathrm{mg}$. A reverse slope for graded doses of a drug is not usual, although not unique; $;^{12}$ the "ceiling" effect which appears to be a feature shared by the majority of mild analgesics, if not by all, is better known.' With nefopam $\mathrm{HCl}$, the clinical impression is that there is a rather low ceiling for its analgesic action. So far only trials with $30 \mathrm{mg}$ and $60 \mathrm{mg}$ doses have been reported.4.5.9.14 It might be that future research will have to be done with higher doses, as the data relating to the ceiling effects of drugs are probably as significant and valuable as an estimate of their relative potency.

The total number of side effects reported and the percentage of patients who admitted secondary reactions are increased ( 76 per cent). In the placebo group only ten patients (40 per cent) complained of side effects and reported 15 secondary reactions; in the active drug group $181 \mathrm{sec}$ ondary reactions occurred in 86 patients. We offer no explanation for this difference between the behaviour of the two groups, which we feel, however, was worth mentioning.

D-propoxyphene produced mainly nervous and integumentary side reactions, similar to the secondary effects reported elsewhere in the literature ${ }^{1,15}$ while nefopam produced sweating. tachycardia and drowsiness in a fair number of patients.

The distribution of the 47 violators between the different groups is almost even, although there were a few more in the nefopam $60 \mathrm{mg}$ and the propoxyphene $65 \mathrm{mg}$ groups. Analysis of the results of all the patients or of the non-violators alone failed to show any differences of statistical significance (Figures 7,8 and 9), demonstrating that the administration of another analgesic drug 
between four and six hours before the study did not potentiate the effect of nefopam or d-propoxyphene. One can also argue reasonably that a four-hour limit, used in the majority of similar drug studies, is adequate for proper assessment of drug effects, as the majority of narcotics (meperidine, codeine) and other analgesics used routinely (acetylsalicylic acid, acetominophen) have a duration of action not much exceeding four hours. ${ }^{16}$ It is likely that the departure from the protocol in 47 cases did not affect the validity of the study.

\section{SUMMARY}

To compare the analgesic activity of nefopam $\mathrm{HCl}$ with d-propoxyphene $\mathrm{HCl}, 85$ male and 40 female in-patients, between 18 and 73 years of age, suffering moderate to severe postoperative pain one to three days after operation, were assigned randomly to one of five treatment groups of 25 patients each. Two groups were given nefopam $\mathrm{HCl}$, one $60 \mathrm{mg}$ and the other $90 \mathrm{mg}$, while two other groups received d-propoxyphene $\mathrm{HCl}, 65 \mathrm{mg}$ and $130 \mathrm{mg}$ respectively. The fifth group received a placebo.

The efficacy of the drugs was assessed double blind by analyzing the pain intensity, pain intensity differences, weighted sum of pain intensity differences, pain relief and weighted total pain relief scores based on a 4-point pain intensity and 5-point pain relief scale determined $0.5,1,2,3,4$, 5 , and 6 hours after the administration of the medication.

The pain relief and weighted sum of pain intensity difference values were most effective in detecting differences between the active drugs and placebo. Pain intensity differences and weighted total pain relief scores were less useful in this respect. The efficacy of d-propoxyphene $130 \mathrm{mg}$ and nefopam $\mathrm{HCl} 60 \mathrm{mg}$ were not significantly different from one another, while each was significantly more effective than placebo. Nefopam $\mathrm{HCl} 90 \mathrm{mg}$ and d-propoxyphene $65 \mathrm{mg}$ and placebo were not significantly different.

Light-headedness, grogginess and drowsiness were reported more frequently for propoxyphene than for placebo; sweating, lachycardia, sleepiness and tiredness were observed more often with nefopam than with placebo. Nefopam caused a greater incidence of sweating than propoxyphene, while the latter was responsible for the more frequent occurrence of a dry mouth and light-headedness than the former.

According to this study, nefopam $\mathrm{HCl} 60 \mathrm{mg}$ was as effective as d-propoxyphene $\mathrm{HCl} 130 \mathrm{mg}$ in alleviating moderate to severe postoperative pain one to three days after operation.

\section{RÉSUMÉ}

L'activité analgésique du nefopam $\mathrm{HCl}$ à des doses de $60 \mathrm{mg}$ et $90 \mathrm{mg}$ et du d-propoxyphene $\mathrm{HCl}$ à des doses de $65 \mathrm{mg}$ et $130 \mathrm{mg}$ fut comparée à celle d'un placebo chez 125 malades des deux sexes, âgés de 18 à 73 ans, qui se plaignaient de douleurs post-opératoires.

L'étude a été faite en double-insu, pendant une période de six heures, au cours de laquelle, à une heure d'intervalle chaque fois, les paramètres suivants ont été relevés, suivant une échelle de zéro à trois (intensité douloureuse) ou de zéro à quatre (allègement de la douleur): intensités douloureuses, variations d'intensité doulourcuse somme des variations d'intensité, allègements de la douleur, somme des allègements. Les paramètres allègements de la douleur et somme des variations d'intensité se montrérent, lors de l'analyse des résultats, plus efficaces que les variations d'intensité douloureuse et la somme des allègements dans la mise en évidence des effets des drogues analgésiques par rapport au placebo.

Les doses de $130 \mathrm{mg}$ de d-propoxyphene et de $60 \mathrm{mg}$ de nefopam $\mathrm{HCl}$, sans pouvoir ètre différenciées les unes des autres, s'avérèrent plus efficaces que le placebo; par contre les effets des doses de $90 \mathrm{mg}$ de nefopam $\mathrm{HCl}$ et de $65 \mathrm{mg}$ de d-propoxyphene ne purent étre distingués de ceux du placebo.

Après avoir pris du propoxyphene certains malades se plaignirent de somnolence, de perte d'équilibre ou de concentration, tandis qu'après le nefopam les malades rapportèrent de la transpiration, de la tachycardie, de la somnolence et de la fatigue.

En conclusion, cette étude montre que des doses de $60 \mathrm{mg}$ de nefopam $\mathrm{HCl}$ et de $130 \mathrm{mg}$ de d-propoxyphene sont également efficaces pour traiter la douleur après une intervention chirurgicale.

\section{REFERENCES}

1. Beaver, W.T. Mild analgesics - A review of their clinical pharmacology. Part l. Amer. J. Med. Sci. 250: 577-604 (1965).

2. BeAVER, W.T. Mild analgesics - A review of their clinical pharmacology. Part II. Amer. J. Med. Sci. 25/: $576-599$ (1966).

3. Klohs, M.W., Drapor, M.D., Petracek, F.J., GınZel. K.H. \& RÉ. O.N. Benzaxocines: a new 
chemical class of centrally acting skeletal muscle relaxants. Arzneimittel-Forshung 22: 132 (1972).

4. COHEN, A. Nefopam hydrochloride for pain relief. Curr. Ther. Res. 16: 184-193 (1974).

5. Workmon, F.C. \& Winter, L. JR. A clinical evaluation of nefopam hydrochioride (Acupan): a new analgesic. Curr. Ther. Res. 16: 609-6.16 (1974).

6. Tigerstedt, I., Sippoven, J., Tammisto, T. \& Turuven, $M$. Comparison of nefopam and pethidine in postoperative pain. Brit. J. Anaesth. 49: 1-133-1138(1977).

7. Sunshine, A. \& Laska, E. Nefopam and morphine in man. Clin. Pharmacol. Ther. 18: 530-534 (1975).

8. Laska, E., Gormley, M., Sunshine, A., Bellville, J.W., Kantor, T.G., Forrest, W.H., Siegel, C. \& MeISNer, M. A bioessay computer program for analgesic clinical trials. Clin. Pharmacol. Ther, 8: 658-669 (1967).

9. KOLODNY. A.L. \& WINTER L., JR. Further clinical evaluations of nefopam hydrochloride: a new analgesic. Curr. Ther. Res. 17: 519-524 (1975).

10. Moertel, C.G., AhmanN, D.L., Taylor, W.F.
\& SCHWARTAN, N. A comparative evaluation of marketed analgesic drugs. New Engl. J. Med. 286: 813-815 (1972).

II. Miller, R.R., Feingold, A. \& Paxinos, J. Propoxyphene hydrochloride: a critical review. J.A.M.A. 213: 996-1006 (1970).

12. CASS, L.J. \& FREDERIK, W.S. Nethopholine, a new analgesic agent. Am. J. Med. Sci. 246: 550-557 (1963).

13. BEECHER, H.K. Evidence for increased effectiveness of placebos with increased stress. Am. J. Physiol. 187: 163-139 (1956).

14. KLOTZ, A.L. Long-term safety of nefopam hydrochloride (Acupan): a new analgesic formulation. Curr. Ther. Res. 16: 602-608 (1974).

15. Gruber JR. C.M., Miller, C.L., Finneran, J. et al. The effectiveness of d-propoxyphene hydrochloride and codeine phosphate, as determined by two methods of clinical testing for relief of chronic pain. J. Pharmacol. Exp. Ther. 118: 280-285 (1956).

16. Goodman, L.S. \& Gilman, A. The Pharmacological Basis of Therapeutics. 5th ed. New York: Macmillan Publishing Co., Inc. (1975). 